\title{
Outcome measures in multimodal rectal cancer trials
}

Citation for published version (APA):

Fokas, E., Glynne-Jones, R., Appelt, A., Beets-Tan, R., Beets, G., Haustermans, K., Marijnen, C., Minsky, B. D., Ludmir, E., Quirke, P., Sebag-Montefiore, D., Garcia-Aguilar, J., Gambacorta, M. A., Valentini, V., Buyse, M., \& Rodel, C. (2020). Outcome measures in multimodal rectal cancer trials. Lancet oncology, 21(5), E252-E264. https://doi.org/10.1016/S1470-2045(20)30024-3

Document status and date:

Published: 01/05/2020

DOI:

10.1016/S1470-2045(20)30024-3

Document Version:

Publisher's PDF, also known as Version of record

Document license:

Taverne

Please check the document version of this publication:

- A submitted manuscript is the version of the article upon submission and before peer-review. There can be important differences between the submitted version and the official published version of record.

People interested in the research are advised to contact the author for the final version of the publication, or visit the DOI to the publisher's website.

- The final author version and the galley proof are versions of the publication after peer review.

- The final published version features the final layout of the paper including the volume, issue and page numbers.

Link to publication

\footnotetext{
General rights Owners
rights.

- You may freely distribute the URL identifying the publication in the public portal. please follow below link for the End User Agreement:

www.umlib.nl/taverne-license

Take down policy

If you believe that this document breaches copyright please contact us at:

repository@maastrichtuniversity.nl

providing details and we will investigate your claim.
}

Copyright and moral rights for the publications made accessible in the public portal are retained by the authors and/or other copyright owners and it is a condition of accessing publications that users recognise and abide by the legal requirements associated with these

- Users may download and print one copy of any publication from the public portal for the purpose of private study or research.

- You may not further distribute the material or use it for any profit-making activity or commercial gain

If the publication is distributed under the terms of Article $25 \mathrm{fa}$ of the Dutch Copyright Act, indicated by the "Taverne" license above, 


\section{Outcome measures in multimodal rectal cancer trials}

\begin{abstract}
Emmanouil Fokas*, Robert Glynne-Jones*, Ane Appelt, Regina Beets-Tan, Geerard Beets, Karin Haustermans, Corrie Marijnen, Bruce D Minsky, Ethan Ludmir, Phil Quirke, David Sebag-Montefiore, Julio Garcia-Aguilar, Maria Antonietta Gambacorta, Vincenzo Valentini, Marc Buyset, Claus Rödel†
\end{abstract}

\begin{abstract}
There is a large variability regarding the definition and choice of primary endpoints in phase 2 and phase 3 multimoda rectal cancer trials, resulting in inconsistency and difficulty of data interpretation. Also, surrogate properties of early and intermediate endpoints have not been systematically assessed. We provide a comprehensive review of clinical and surrogate endpoints used in trials for non-metastatic rectal cancer. The applicability, advantages, and disadvantages of these endpoints are summarised, with recommendations on clinical endpoints for the different phase trials, including limited surgery or non-operative management for organ preservation. We discuss how early and intermediate endpoints, including patient-reported outcomes and involvement of patients in decision making, can be used to guide trial design and facilitate consistency in reporting trial results in rectal cancer.
\end{abstract}

\section{Introduction}

Rectal cancer is among the best examples in oncology of how progress is derived from multimodal treatment. Preoperative fluorouracil based chemoradiotherapy or short-course radiotherapy followed by total mesorectal excision have substantially reduced locoregional recurrence. However, most trials did not show an improvement in disease-free survival or overall survival., ${ }^{1,2}$

In phase 3 cancer trials, overall survival is the most objectively defined endpoint and is considered the standard measure of treatment efficacy. Overall survival requires a large sample size, and long-term follow-up is costly and carries risk of the investigated treatment losing novelty by the time the trial is completed. Overall survival can be confounded by effective successive treatment lines in case of disease progression or recurrence, and competing risks for non-cancer related deaths, especially among older and frail patients, might reduce the observed treatment effect. ${ }^{3}$ There has been an increased interest in early or intermediate endpoints as surrogate measures of long-term endpoints in oncology trials. ${ }^{4}$

As outcome measures have been derived at several different timepoints during and after multimodal treatment, rectal cancer could address the complex interplay between early, intermediate, and long-term endpoints (figure 1). Here, we review surrogate and clinical endpoints used in non-metastatic rectal cancer in randomised multimodal clinical trials, including those of limited or non-operative management for organ preservation. The applicability, advantages and disadvantages of endpoints are summarised. This Review focuses mostly on the neoadjuvant setting. The effect of rectal cancer treatment on quality of life (QOL) has been increasingly recognised and might be as important for patients, thus we also outline patient-reported outcomes (PROs) in rectal cancer. Finally, we discuss how early and intermediate endpoints could be used to guide trial design and facilitate consistency in reporting trial results in rectal cancer.

Early endpoints for tumour response at surgery

Tumour response to chemoradiotherapy and shortcourse radiotherapy varies considerably in rectal cancer.
Early variables to assess tumour response, such as downstaging, pathological complete response, tumour regression grading, the neoadjuvant rectal score, completeness of local resection, and circumferential resection margin, have been proposed to reflect treatment effectiveness and patient prognosis, and have been suggested as potential surrogates for long-term outcomes, such as locoregional recurrence, disease-free survival, and overall survival (figure 1).

Tumour response is a dynamic process associated with tumour-related factors (eg, size, histology, and molecular profile) and treatment-related factors (such as radiotherapy dose and fractionation, chemotherapy, and the time between neoadjuvant treatment and surgery). The complex interplay between these factors and the varying timepoints of response assessment makes interpretation of early efficacy endpoints challenging. Although an increased tumour response might predict favourable outcomes of individual patients receiving one type of treatment, differences in early efficacy endpoints induced by different treatments might not be valid surrogates for long-term oncological outcomes. For example, the Polish $\mathrm{I}^{5}$ and Trans-Tasman ${ }^{6}$ randomised trials, of short-course radiotherapy followed by immediate surgery versus fluorouracil chemoradiotherapy followed by delayed surgery, showed significantly increased pathological downstaging and pathological complete response in the fluorouracil chemoradiotherapy group, yet, no improvement in locoregional recurrence, disease-free survival, or overall survival.

The basic requirement for a surrogate endpoint is that changes of this endpoint between treatment interventions should translate to changes of the true clinical endpoints. Establishing surrogate endpoints is challenging as it requires rigorous statistical validation using large trial datasets. In 1989, Prentice proposed four criteria to validate surrogacy. ${ }^{7}$ First, the treatment must significantly impact on the true clinical endpoint. Second, the treatment must have a significant effect on the surrogate endpoint. Third, the surrogate endpoint must have a statistically significant effect on the true endpoint, and fourth, the full effect of treatment on the

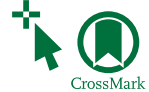
CrossMark

ancet Oncol 2020; 21: e252-64 *Joint first authors †joint last authors

Department of Radiotherapy and Oncology, University of Frankfurt, Frankfurt, Germany (Prof E Fokas MD, Prof ( Rödel MD); German Cancer Consortium, German Cancer Research Center, Heidelberg, Germany (Prof E Fokas, Prof C Rödel); Frankfurt Cancer Institute, Frankfurt Germany (Prof E Fokas, Prof C Rödel); Department of Radiotherapy, Mount Vernon Cancer Centre, Northwood, UK (R Glynne-Jones MRCP); Institute of Medical Research at St James's, University of Leeds, Leeds, UK (A Appelt PhD, Prof D Sebag-Montefiore FRCR); Department of Radiology (Prof R Beets-Tan MD), Department of Surgery (Prof G Beets MD), Department of Radiation Oncology (Prof C Marijnen MD), The Netherlands Cancer Institute, Amsterdam, Netherlands; GROW School for Oncology and Developmental Biology, Maastricht University, Maastricht, Netherlands (Prof R Beets-Tan, Prof G Beets); Department of Radiation Oncology, University Hospital Leuven, Leuven, Belgium (Prof K Haustermans), Department of Radiation Oncology, The University of Texas MD Anderson Cancer Center, Houston, TX, USA (Prof B D Minsky MD, E Ludmir MD); Division of Pathology and Data Analytics, School of Medicine, Leeds University, Leeds, UK (Prof P Quirke FRCPath); Department of Surgery, Memorial Sloan Kettering Cancer Center, New York, NY, USA (ProfJ Garcia-Aguilar MD); Department of Radiation Oncology, Fondazione Policlinico Universitario Agostino Gemelli IRCCS, Università Cattolica del Sacro Cuore, Rome, Italy (Prof M A Gambacorta MD Prof V Valentini MD); 


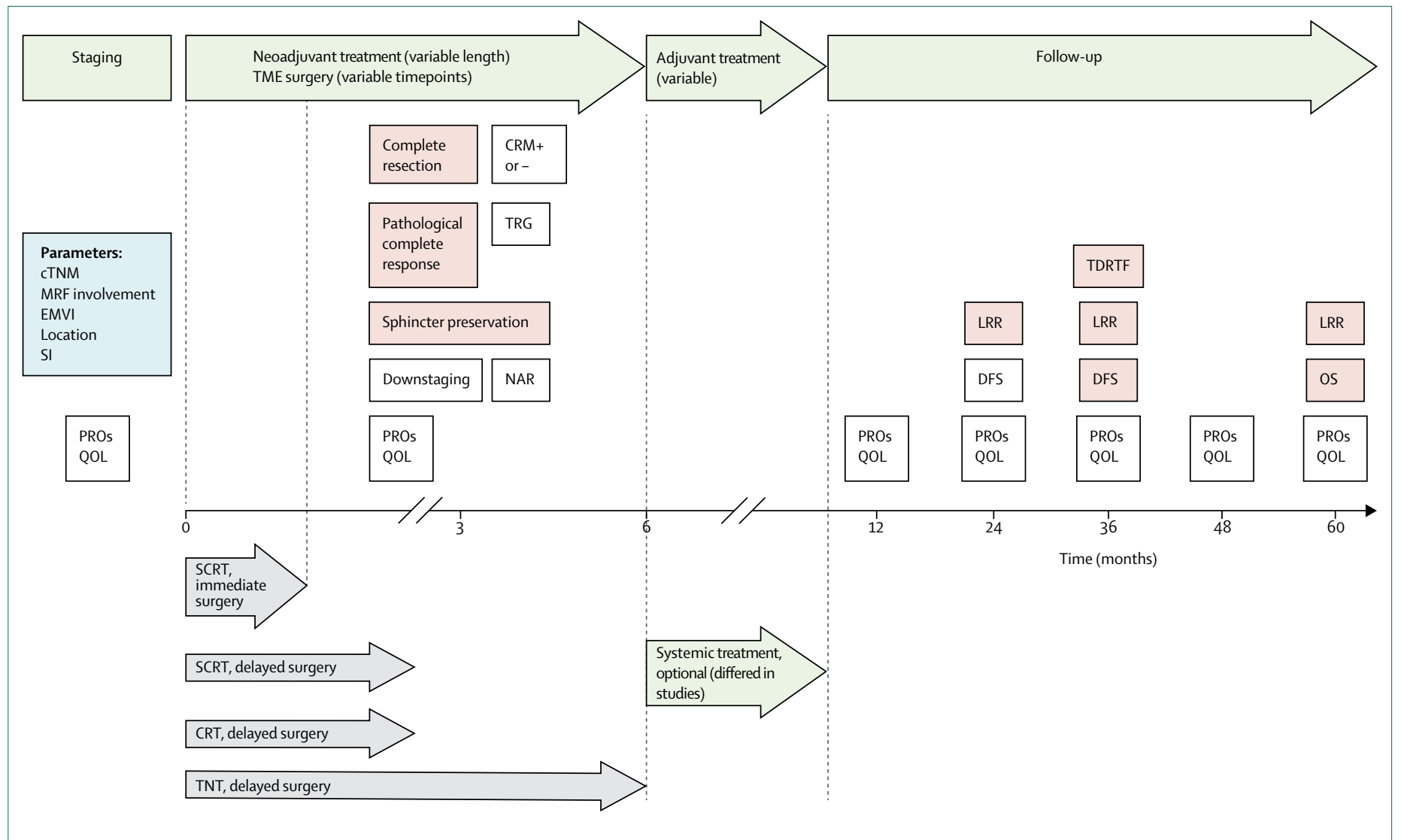

Figure 1: Clinical outcome measures for rectal cancer after neoadjuvant treatment and TME

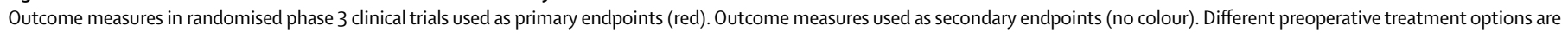

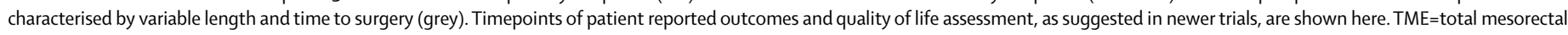
excision. $\mathrm{CTNM}=$ clinical tumour node metastasis. $\mathrm{MRF}=$ mesorectal fascia. EMVI=extramural venous invasion. SI=sphincter involvement. PROs=patient-reported outcomes. QOL=quality of life.

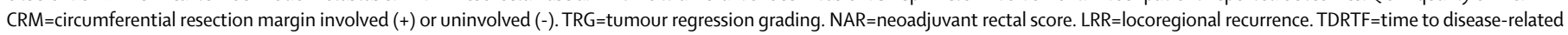
treatment failure. DFS=disease-free survival. OS=overall survival. SCRT=short-course radiotherapy. $C R T=$ chemoradiotherapy. $T N T=$ total neoadjuvant therapy.

Interuniversity Institute for Biostatistics and Statistical Bioinformatics, Hasselt University, Diepenbeek, Belgium (Prof M Buyse ScD); and International Drug Development Institute, San Francisco, CA, USA (Prof M Buyse)

Correspondence to: Prof Emmanouil Fokas, Department of Radiotherapy and Oncology, University of Frankfurt, 60590 Frankfurt, Germany emmanouil.fokas@kgu.de true endpoint should be captured by the surrogate endpoint. However, the last criterion is characterised by methodological limitations in interpretation. An alternative validation method has been established based on the correlation approach that involves showing surrogacy at two levels. ${ }^{48}$ First, individual-level endpoint surrogacy reflects the correlation of surrogate outcome with clinical outcome, and can be shown in a single trial dataset using standard correlation coefficients. Secondly, trial-level endpoint surrogacy is based on meta-analysis of phase 3 trials.

\section{Downstaging}

Downstaging is a decrease of the pathological versus the preoperative clinical $\mathrm{T}$ category or $\mathrm{N}$ category, or both, and has been used as an endpoint in early trials to evaluate the effectiveness of preoperative chemoradiotherapy and short-course radiotherapy. The CAO/ ARO/AIO-94 trial ${ }^{2}$ showed that preoperative chemoradiotherapy induced significant downstaging compared with straight surgery. The subgroup of patients who had
ypT0N0 or ypT1-2N0 disease after preoperative chemoradiotherapy had an excellent prognosis; however, patients with remaining ypT3-4 or ypN1-2 after preoperative chemoradiotherapy had a higher risk of developing distant metastases with poorer disease-free survival compared with patients with corresponding pathological tumour, node, metastasis (TNM) subgroups in the postoperative treatment group. Diseasefree and overall survival remained identical in both groups, resembling the reverse Will Rogers stage migration phenomenon. ${ }^{9}$ Thus, downstaging might unmask different prognostic subgroups within a given treatment group, rather than reflect improved treatment efficacy between interventions. Also, there is no clear definition of downstaging, which makes its use challenging. Some investigators used a reduction of either $\mathrm{T}$ or $\mathrm{N}$ categories by at least one level, whereas others restricted this endpoint to a reduction of stage. As such, validation of downstaging as a surrogate endpoint based on large phase 3 trial cohorts is currently unavailable. 


\begin{tabular}{|c|c|c|c|}
\hline & $\begin{array}{l}\text { Number of } \\
\text { patients }\end{array}$ & Treatment schedule and time to surgery & $\begin{array}{l}\text { Primary clinical } \\
\text { endpoint }\end{array}$ \\
\hline Lyon R90-01 trials ${ }^{10,11}$ & 210 & $\begin{array}{l}\text { Radiotherapy followed by } 2 \text {-week interval to surgery versus radiotherapy followed by } 6-8 \text { weeks } \\
\text { interval to surgery }\end{array}$ & $\begin{array}{l}\text { Sphincter-sparing } \\
\text { surgery }\end{array}$ \\
\hline GRECCAR- 6 trial $^{12}$ & 265 & $\begin{array}{l}\text { Fluorouracil or capecitabine chemoradiotherapy followed by } 7 \text {-week interval to surgery versus } \\
\text { chemoradiotherapy followed by 11-week interval to surgery }\end{array}$ & $\begin{array}{l}\text { Pathological } \\
\text { complete response }\end{array}$ \\
\hline British trial ${ }^{13}$ & 237 & $\begin{array}{l}\text { Capecitabine chemoradiotherapy followed by } 6 \text {-week interval to surgery versus capecitabine } \\
\text { chemoradiotherapy followed by } 12 \text {-week interval to surgery }\end{array}$ & $\begin{array}{l}\text { MRI-based } \\
\text { T-downstaging }\end{array}$ \\
\hline Turkish trial $^{14}$ & 327 & $\begin{array}{l}\text { Capecitabine chemoradiotherapy followed by less than } 8 \text {-weeks interval to surgery versus } \\
\text { capecitabine chemoradiotherapy followed by more than 8-weeks interval to surgery }\end{array}$ & $\begin{array}{l}\text { Pathological } \\
\text { complete response }\end{array}$ \\
\hline Stockholm III trial'15 & 840 & $\begin{array}{l}\text { Short-course radiotherapy followed by surgery within } 1 \text {-week versus short-course radiotherapy } \\
\text { followed by surgery after 4-8 weeks versus long-course radiotherapy followed by surgery } \\
\text { after 4-8 weeks }\end{array}$ & $\begin{array}{l}\text { Time to local } \\
\text { recurrence }\end{array}$ \\
\hline
\end{tabular}

\section{Pathological complete response}

Pathological complete response is the primary endpoint in numerous phase 1, 2, and 3 trials (tables 1-3). Maas and colleagues ${ }^{39}$ showed a strong association of pathological complete response after chemoradiotherapy with improved disease-free survival and overall survival. The excellent prognosis of patients with pathological complete response could be, in part, explained by possible overstaging and overtreating early-stage tumours. Pooled individual data analysis ${ }^{40}$ from the EORTC 22921 and FFCD 9203 phase 3 trials comparing the effect of preoperative radiotherapy with or without concurrent fluorouracil showed significantly higher pathological complete response rates and reduced 3-year locoregional recurrence in the chemoradiotherapy versus radiotherapy groups, but no significant improvement in overall survival and poor trial-level surrogacy of pathological complete response for overall survival. Similarly, in a meta-analysis of 22 randomised trials ${ }^{41}$ involving 10050 patients treated with neoadjuvant radiotherapy or chemoradiotherapy, the pathological complete response was poorly correlated with 5 -year overall survival, both at the individual and trial level. Thus, intensification of local neoadjuvant treatment by increasing radiotherapy dose or adding radiosensitising drugs could improve pathological complete response rates and potentially reduce locoregional recurrence; however, the natural history of the disease with respect to distant metastases might not be improved.

In the Lyon R90-01 randomised trial, ${ }^{10}$ a longer interval (6-8 weeks vs 2 weeks) between completion of radiotherapy and surgery led to significant increase of patients with major pathological response (pathological complete response or few residual cells) without an effect on locoregional recurrence or overall survival. Further extension beyond 8 weeks has been tested in the GRECCAR-6 trial ${ }^{12}$ (7 weeks vs 11 weeks) and a British randomised trial ( 6 weeks vs 12 weeks).$^{13}$ Although the GRECCAR-6 trialdid not show an increase of pathological complete response in the longer interval group (15\% vs $17 \cdot 4 \%, p=0 \cdot 59)$, the British study did find a statistical increase ( $9 \%$ vs $20 \%, \mathrm{p}<0 \cdot 05)$. Similarly, an increased pathological complete response $(18 \%$ vs $10 \%, \mathrm{p}=0.027)$ was also reported by Akgun and colleagues ${ }^{14}$ for an interval of more than 8 weeks versus less than 8 weeks after chemoradiotherapy. Long-term outcomes of these trials are pending (table 1). The available trial data are conflicting and do not suggest that simply increasing the interval beyond 6-8 weeks will result in better long-term outcomes. Also, most studies had a small sample size, which should be considered when interpreting the findings.

Several groups have used the prolonged interval time between chemoradiotherapy or short-course radiotherapy and surgery for adding neoadjuvant, rather than adjuvant chemotherapy, known as total neoadjuvant treatment. A prospective phase 2 cohort trial ${ }^{42}$ used preoperative chemoradiotherapy and sequentially increased the timepoint of surgery. Group 1 underwent surgery 6 weeks after completion of chemoradiotherapy. Groups 2, 3, and 4 received two, four, or six cycles of FOLFOX (leucovorin, fluorouracil, and oxaliplatin) during the waiting period before surgery that was done at 11, 15, and 19 weeks, after completion of chemoradiotherapy. The pathological complete response rate of patients treated in study group 1 was $18 \%$ compared with $25 \%$ (group 2), $30 \%$ (group 3), and $38 \%$ (group 4)..$^{42}$ Whether prolonging the interval between radiotherapy and surgery and adding systemic therapy will lead to improved disease-free survival and increased organ preservation, is currently being tested in the OPRA phase 2 trial (NCT02008656) and the RAPIDO phase 3 trial after SCRT (NCT01558921). The CAO/ARO/ AIO-12 randomised phase 2 trial that compared two total neoadjuvant treatments (chemoradiotherapy with either induction or consolidation chemotherapy), showed a pathological complete response of $17 \%$ (chemoradiotherapy and induction) and 25\% (chemoradiotherapy and consolidation chemotherapy). ${ }^{20}$ However, long-term data are needed to show whether improved pathological complete response translates into improved disease-free survival (table 2).

\section{Lymph node status}

Lymph node status after preoperative chemoradiotherapy or short-course radiotherapy is an important prognostic 
patients

\begin{tabular}{lcl}
\hline Randomised phase 2 trials testing TNT \\
\hline $\mathrm{GCdr}^{16} 3^{16}$ & 108 & $\begin{array}{l}\text { Capecitabine plus oxaliplatin CRT followed by surgery and adjuvant CAPOX versus } \\
\text { induction CAPOX chemotherapy followed by capecitabine plus oxaliplatin CRT and } \\
\text { surgery }\end{array}$ \\
${\text { EXPERT-C }{ }^{17}}^{17}$ & $\begin{array}{l}\text { Induction CAPOX chemotherapy and cetuximab followed by capecitabine plus cetuximab } \\
\text { CRT and surgery versus CAPOX chemotherapy followed by capecitabine CRT and surgery }\end{array}$
\end{tabular}

GEMCAD $1402^{18} \quad 115$

GRECCAR4 $^{19}$

194

CAO/ARO/AIO- $12^{20} \quad 304$

OPRA

(NCT02008656)

NRG GI002

(NCT02921256)

\section{Induction mFOLFOX6 chemotherapy and aflibercept followed by capecitabine CRT and} surgery versus induction mFOLFOX6 chemotherapy followed by capecitabine CRT and surgery

Induction FOLFIRINOX followed by immediate surgery versus capecitabine CRT and surgery (good responders); or induction FOLFIRINOX followed by capecitabine CRT (50 $\mathrm{Gy}$ ) and surgery versus capecitabine CRT (60 Gy) and surgery (poor responders) Induction mFOLFOX6 chemotherapy followed by 5-FU plus oxaliplatin CRT and surgery versus 5 -FU plus oxaliplatin CRT followed by mFOLFOX6 chemotherapy and surgery Induction mFOLFOX6 chemotherapy followed by 5-FU CRT and surgery or NOM versus 5-FU CRT followed by mFOLFOX6 chemotherapy and surgery or NOM

178

Induction FOLFOX chemotherapy followed by capecitabine chemotherapy followed by capecitabine plus veliparib CRT versus induction FOLFOX chemotherapy followed by capecitabine plus pembrolizumab CRT

\section{Randomised phase 2 and 3 trials testing NOM and LE or TEM}

\begin{tabular}{|c|c|c|c|}
\hline $\begin{array}{l}\text { Brazilian trial } \\
\text { (NCT02052921) }\end{array}$ & 150 & $\begin{array}{l}\text { 5-FU CRT followed by observation versus } 5 \text {-FU CRT followed by TME surgery after } \\
\text { achieving complete clinical response at } 12 \text { weeks }\end{array}$ & 3-year disease-free survival \\
\hline $\begin{array}{l}\text { TESAR } \\
\text { (NCT02371304) }\end{array}$ & 302 & TME surgery versus LE followed by capecitabine CRT & 3-year locoregional recurrence \\
\hline $\begin{array}{l}\text { OPERA } \\
\text { (NCT02505750) }\end{array}$ & 236 & $\begin{array}{l}\text { Capecitabine CRT followed by EBRT boost versus capecitabine CRT followed by } \\
\text { brachytherapy boost (if complete clinical response: NOM or LE; if partial response: TME) }\end{array}$ & 3-year organ preservation* \\
\hline $\begin{array}{l}\text { WW3 } \\
\text { (NCT04095299) }\end{array}$ & 111 & $\begin{array}{l}\text { Capecitabine CRT versus capecitabine CRT with SIB (if complete clinical response: NOM or } \\
\text { LE; if partial response: TME) }\end{array}$ & 2-year organ preservation* \\
\hline $\begin{array}{l}\text { MORPHEUS } \\
\text { (NCT03051464) }\end{array}$ & 40 & $\begin{array}{l}\text { Capecitabine CRT followed by EBRT boost versus capecitabine CRT followed by } \\
\text { brachytherapy boost (if complete clinical response: NOM; if partial response: TME) }\end{array}$ & 2-year organ preservation \\
\hline $\begin{array}{l}\text { GRECCAR12 } \\
\text { (NCT02514278) }\end{array}$ & 218 & $\begin{array}{l}\text { Induction } \mathrm{mFOLFIRINOX} \text { followed by capecitabine CRT versus capecitabine CRT (if good } \\
\text { response: LE; if poor response: TME) }\end{array}$ & $\begin{array}{l}\text { 12-month organ } \\
\text { preservation† }\end{array}$ \\
\hline $\begin{array}{l}\text { TESS } \\
\text { (NCT03840239) }\end{array}$ & 168 & $\begin{array}{l}\text { Induction CAPOX chemotherapy followed by capecitabine plus oxaliplatin CRT versus } \\
\text { capecitabine plus oxaliplatin CRT (if complete clinical response: NOM; if partial response: } \\
\text { LE or TEM; if poor response: TME) }\end{array}$ & $\begin{array}{l}\text { Sphincter preservation (stoma } \\
\text { absence) at } 18 \text { months }\end{array}$ \\
\hline $\begin{array}{l}\text { STARTREC } \\
\text { (NCT02945566) }\end{array}$ & 120 & $\begin{array}{l}\text { TME surgery versus capecitabine CRT followed by NOM versus SCRT followed by NOM } \\
\text { (if complete clinical response: NOM; if partial response: TEM; if poor response: TME) }\end{array}$ & $\begin{array}{l}\text { Recruitment rate at } \\
12 \text { and } 24 \text { months } \ddagger\end{array}$ \\
\hline $\begin{array}{l}\text { TREC (ISRCTN } \\
14422743)\end{array}$ & .. & TME surgery versus SCRT followed by TEM or NOM & $\begin{array}{l}\text { Recruitment rate at } 12,18, \\
\text { and } 24 \text { months } \ddagger\end{array}$ \\
\hline $\begin{array}{l}\text { APHRODITE } \\
(\text { ISRCTN16158514) }\end{array}$ & 104 & $\begin{array}{l}\text { 5-FU or capecitabine CRT versus 5-FU or capecitabine CRT with SIB (if complete clinical } \\
\text { response: NOM) }\end{array}$ & $\begin{array}{l}\text { Complete clinical response at } \\
6 \text { months }\end{array}$ \\
\hline
\end{tabular}

All trials shown above are phase 2, except the OPERA and GRECCAR12, which are randomised phase 3 trials. MORPHEUS is a pilot randomised trial. TNT=total neoadjuvant therapy. CRT=chemoradiotherapy. CAPOX=capecitabine and oxaliplatin. FOLFIRINOX=fluorouracil, leukovorin, irinotecan, and oxaliplatin). 5-FU=5-fluorouracil. $\mathrm{NOM}=$ non-operative management. FOLFOX=fluorouracil, leucovorin, and oxaliplatin. TME=total mesorectal excision. LE=local excision. EBRT=external beam radiotherapy $\mathrm{SIB}=$ simultaneously integrated boost. TEM=transanal endoscopic microsurgery. SCRT=short-course radiotherapy. *In the OPERA trial, organ preservation is defined as the rate of rectum preservation, either with local excision or watch and wait strategy after neoadjuvant treatment, without non-salvageable locally progressive disease at 3 years post-treatment, or permanent stoma; in the WW3 trial, organ preservation is defined as an intact rectum, no locoregional failure, and no stoma at 2 years post-treatment. tIn the GRECCAR12 trial, organ preservation is defined as the number of patients with organ preservation and absence of stoma, 1 year after surgery. $\neq$ The aim of these studies is to assess the feasibility of recruitment within the phase 2 trial.

Table 2: Primary clinical endpoints in trials for total neoadjuvant therapy with or without NOM and LE or TEM

factor for both local and distant recurrence. ${ }^{43}$ In the CAO/ ARO/AIO-04 trial, ${ }^{44}$ the 3-year cumulative incidence of locoregional recurrence and distant recurrences were $2 \%$ and $10 \cdot 6 \%$ for ypN0, $2 \cdot 5 \%$ and $28 \cdot 6 \%$ for ypN1, and $17.2 \%$, and $48 \%$ for ypN2, respectively. Persistent lymph node metastases after neoadjuvant chemoradiotherapy reflect a highly aggressive tumour phenotype resistant towards chemoradiotherapy and prone to distant metastases.

\section{Neoadjuvant rectal score}

The neoadjuvant rectal (NAR) score was proposed as a potential surrogate for overall survival in rectal cancer. ${ }^{45}$ The NAR formula $\left.(5 \mathrm{ypN}-3[\mathrm{cT}-\mathrm{ypT}]+12]^{2} / 9 \cdot 61\right)$ results 


\begin{tabular}{|c|c|c|c|}
\hline & $\begin{array}{l}\text { Number of } \\
\text { patients }\end{array}$ & Treatment schedule & Primary clinical endpoint \\
\hline Swedish trial $^{21}$ & 1168 & Surgery with or without preoperative SCRT & 5-year overall survival \\
\hline NSABP R03 $3^{22}$ & 267 & $\begin{array}{l}\text { Preoperative versus postoperative 5-FU plus LV CRT followed by surgery and adjuvant } \\
\text { 5-FU plus LV chemotherapy }\end{array}$ & $\begin{array}{l}\text { 5-year disease-free survival } \\
\text { and overall survival }\end{array}$ \\
\hline Frykholm ${ }^{23}$ & 70 & $\begin{array}{l}\text { Preoperative methotrexate plus 5-FU plus LV CRT versus RT followed by surgery and } \\
\text { adjuvant chemotherapy }\end{array}$ & 5-year local recurrence \\
\hline Dutch trial ${ }^{24}$ & 1861 & Surgery with or without preoperative SCRT & 2-year local recurrence \\
\hline CAO/ARO/AIO- $94^{25}$ & 823 & $\begin{array}{l}\text { Preoperative versus postoperative 5-FU CRT followed by surgery and adjuvant 5-FU } \\
\text { chemotherapy }\end{array}$ & 5-year overall survival \\
\hline Polish | trial ${ }^{5}$ & 316 & $\begin{array}{l}\text { Preoperative 5-FU plus LV CRT versus SCRT followed by surgery and adjuvant } \\
\text { chemotherapy }\end{array}$ & Sphincter preservation \\
\hline Braendengen ${ }^{26}$ & 207 & $\begin{array}{l}\text { Preoperative methotrexate plus 5-FU plus LV CRT versus RT followed by surgery and } \\
\text { adjuvant chemotherapy }\end{array}$ & 5-year overall survival \\
\hline EORTC $22921^{27}$ & 1011 & $\begin{array}{l}\text { Preoperative 5-FU plus LV CRT versus RT alone followed by surgery and adjuvant 5-FU } \\
\text { plus LV chemotherapy versus observation }\end{array}$ & 5-year overall survival \\
\hline FFCD $9203^{28}$ & 762 & $\begin{array}{l}\text { Preoperative 5-FU CRT plus LV CRT versus RT followed by surgery and adjuvant 5-FU } \\
\text { plus LV chemotherapy }\end{array}$ & 5-year overall survival \\
\hline $\begin{array}{l}\text { MRC CR07 and } \\
\text { NCIC-CTG C016 }\end{array}$ & 1350 & $\begin{array}{l}\text { Preoperative SCRT and surgery versus surgery followed by selective postoperative CRT } \\
\text { (CRM-positive only) }\end{array}$ & 3-year local recurrence \\
\hline STAR- $01^{30}$ & 747 & $\begin{array}{l}\text { Preoperative 5-FU CRT versus 5-FU plus oxaliplatin CRT followed by surgery and } \\
\text { adjuvant chemotherapy }\end{array}$ & 5 -year overall survival \\
\hline $\begin{array}{l}\text { ACCORD 12/0405 } \\
\text { PRODIGE 2 }\end{array}$ & 598 & $\begin{array}{l}\text { Preoperative capecitabine CRT versus capecitabine plus oxaliplatin CRT followed by } \\
\text { surgery and adjuvant chemotherapy }\end{array}$ & $\begin{array}{l}\text { Pathological complete } \\
\text { response }\end{array}$ \\
\hline NASBP R-04 $4^{32}$ & 1608 & $\begin{array}{l}\text { Preoperative capecitabine CRT versus capecitabine plus oxaliplatin CRT versus 5-FU } \\
\text { CRT versus 5-FU plus oxaliplatin CRT, all followed by surgery and adjuvant } \\
\text { chemotherapy }\end{array}$ & 3-year Local recurrence \\
\hline PETACC-633 & 1094 & $\begin{array}{l}\text { Preoperative capecitabine CRT versus capecitabine plus oxaliplatin CRT followed by } \\
\text { surgery and adjuvant chemotherapy with or without oxaliplatin }\end{array}$ & 3-year disease-free survival \\
\hline Hofheinz $z^{34}$ & 401 & $\begin{array}{l}\text { Preoperative or postoperative 5-FU CRT versus capecitabine CRT followed by surgery } \\
\text { and adjuvant chemotherapy }\end{array}$ & 5-year overall survival \\
\hline CAO/ARO/AIO- $04^{35}$ & 1236 & $\begin{array}{l}\text { Preoperative 5-FU CRT versus 5-FU plus oxaliplatin CRT followed by surgery and } \\
\text { adjuvant chemotherapy with or without oxaliplatin }\end{array}$ & 3-year disease-free survival \\
\hline FOWARC ${ }^{36}$ & 495 & $\begin{array}{l}\text { Preoperative 5-FU plus LV CRT versus 5-FU plus LV plus oxaliplatin CRT versus FOLFOX6 } \\
\text { chemotherapy followed by surgery and adjuvant chemotherapy }\end{array}$ & 3-year disease-free survival \\
\hline Stockholm IIII & 840 & $\begin{array}{l}\text { SCRT and surgery within } 1 \text {-week versus SCRT followed by surgery after } 4-8 \text { weeks } \\
\text { versus long-course RT followed by surgery after } 4-8 \text { weeks }\end{array}$ & Time to local recurrence \\
\hline Polish $\|^{37}$ & 515 & $\begin{array}{l}\text { SCRT and consolidation FOLFOX4 versus 5-FU plus LV (plus oxaliplatin) CRT followed } \\
\text { by surgery and adjuvant chemotherapy }\end{array}$ & RO resection rate \\
\hline GRECCAR-2 $2^{38}$ & 186 & Preoperative CRT followed by local excision versus TME surgery & 2-year composite endpoint* \\
\hline $\begin{array}{l}\text { ARISTOTLE } \\
\text { (ISRCTN09351447) }\end{array}$ & 600 & $\begin{array}{l}\text { Preoperative capecitabine CRT versus capecitabine plus irinotecan CRT followed by } \\
\text { surgery and adjuvant chemotherapy }\end{array}$ & 3-year disease-free survival \\
\hline $\begin{array}{l}\text { RAPIDO } \\
\text { (NCT01558921) }\end{array}$ & 920 & $\begin{array}{l}\text { Preoperative CRT followed by TME surgery versus SCRT followed by CAPOX or FOLFOX } \\
\text { consolidation chemotherapy and TME surgery }\end{array}$ & $\begin{array}{l}\text { Time to disease-related } \\
\text { treatment failure }\end{array}$ \\
\hline $\begin{array}{l}\text { PROSPECT (NCCTG } \\
\text { N1048/Alliance; } \\
\text { NCT01515787) }\end{array}$ & 1194 & $\begin{array}{l}\text { Induction FOLFOX chemotherapy followed by surgery (response }>20 \% \text { ) or CRT and } \\
\text { surgery (response }<20 \% \text { ) versus CRT followed by surgery and adjuvant FOLFOX } \\
\text { chemotherapy }\end{array}$ & $\begin{array}{l}\text { Local recurrence and 3-year } \\
\text { disease-free survival }\end{array}$ \\
\hline $\begin{array}{l}\text { STAR TREC (Phase } 3 \\
\text { part; NCT02945566) }\end{array}$ & 460 & $\begin{array}{l}\text { TME surgery versus capecitabine CRT versus SCRT (if complete clinical response: NOM; } \\
\text { if partial response: TEM; if poor response: TME) }\end{array}$ & $\begin{array}{l}\text { 30-month organ preservation } \\
\text { rate }\end{array}$ \\
\hline $\begin{array}{l}\text { ACO/ARO/AIO-18.1 } \\
\text { (EudraCT: } \\
\text { 2018-000876-14) }\end{array}$ & 822 & $\begin{array}{l}\text { Preoperative 5-FU plus oxaliplatin CRT followed by consolidation FOLFOX } \\
\text { chemotherapy and TME surgery (or NOM by complete clinical response) versus 5-FU } \\
\text { CRT followed by TME surgery (or NOM by complete clinical response) }\end{array}$ & 3-year disease-free survival \\
\hline \multicolumn{4}{|c|}{$\begin{array}{l}\text { In the STAR TREC trial (phase 3), organ preservation is defined as an intact rectum, no locoregional failure, and no stoma. SCRT=short-course radiotherapy. } 5 \text {-FU=fluorourac } \\
\text { LV=leucovorin. CRT=chemoradiotherapy. RT=radiotherapy. CRM=circumferential resection margin. FOLFOX=folinic acid, leukovorin, oxaliplatin. TME=total mesorectal } \\
\text { excision. CAPOX=capecitabine, oxaliplatin. NOM=non-operative management. }{ }^{*} \text { The primary clinical endpoint in the GRECCAR-2 trial was a composite outcome of death, } \\
\text { recurrence, morbidity, and side-effects at 2-years after surgery. }\end{array}$} \\
\hline
\end{tabular}

in 24 distinct scores that range from 0 to 100 . For ypT and ypN, a relative weight of 3 and 5 has been suggested to reflect the effect of these variables, based on the nomogram of Valentini and colleagues. ${ }^{46}$ The NAR score was classified as low $(\mathrm{NAR}<8)$, intermediate $(\mathrm{NAR}=8-16)$, and high (NAR $>16$ ) according to the score tertiles of the 
randomised NSABP R-04 trial dataset. A lower NAR score was associated with improved overall survival.

The individual-level endpoint surrogacy of NAR for disease-free survival was shown in the CAO/ARO/AIO-04 trial $^{47}$ using Prentice criteria. Addition of oxaliplatin to preoperative fluorouracil chemoradiotherapy resulted in significant disease-free survival improvement, which was reflected in a pronounced shift towards lower NAR scores at surgery. The NAR score was an independent predictor, capturing the treatment effect on disease-free survival. Yothers and colleagues ${ }^{48}$ showed a small but significant association between change in NAR score and improvement in overall survival $\left(\mathrm{r}^{2}=0 \cdot 13\right)$ by meta-analysis of five randomised trials of neoadjuvant treatment. This trial-level association was nominally better than the association for pathological complete response and overall survival $\left(\mathrm{r}^{2}=0 \cdot 02\right) .{ }^{48}$ The prognostic value of NAR was also confirmed in the PAN-EX, ${ }^{49}$ a pooled analysis of the EXPERT and EXPERT-C phase 2 trials that tested induction chemotherapy followed by chemoradiotherapy in patients with high-risk rectal cancer.

NAR is currently used as primary endpoint in the NRG GI002 phase 2 trial $^{50}$ (NCT02921256) for total neoadjuvant treatment to assess novel radiosensitisers (table 2). The addition of veliparib, a PARP inhibitor, to standard chemoradiotherapy after induction of FOLFOX chemotherapy did not reach the primary endpoint of the trial, which was a 4-point reduction in the NAR score.

\section{Tumour regression grading}

Tumour regression grading (TRG) is a semiquantitative assessment of residual tumour cells versus fibroinflammatory tissue in the rectal wall after preoperative treatment. There is no consensus for a universally approved standardisation method, and the studies using TRG were characterised by heterogeneity regarding methodological assessment, patient cohort, treatment modality, and the time interval between chemoradiotherapy and surgery. ${ }^{52}$ Data from the CAO/ARO/AIO-94 and CAO/ARO/AIO-04 studie ${ }^{2,35}$ suggest that TRG identified distinct prognostic groups independent of prognostic factors, such as the TNM classification system, and fulfilled the Prentice criteria for individual-level surrogacy, ${ }^{43,44}$ similarly to the NAR score ${ }^{47} \mathrm{~A}$ shift of 24 scores as in the case of NAR, or 3-5 tier semiquantitative TRG, could reflect treatment effects induced by different neoadjuvant regimens more accurately than binary endpoints, such as downstaging or pathological complete response, and these treatmentinduced changes are potentially better candidate surrogate endpoints for overall survival (appendix p 1).

The MRI-based TRG (MRI-TRG) was used as an endpoint in the MERCURY trial ${ }^{53}$ to stratify patients with a poor response (MRI-TRG 4-5) and a good response (MRI-TRG 1-3). A significantly worse disease-free survival and overall survival was reported among patients with a poor response. A weak correlation between MRI-TRG and pathological TRG was reported in the
EXPERT and EXPERT-C phase 2 trials, ${ }^{54}$ thus further studies to assess the applicability of MRI-TRG as an endpoint are needed. The TRIGGER randomised feasibility trial (NCT02704520) is currently assessing the potential of MRI to guide treatment selection, including deferral of surgery, according to the MRI-TRG after chemoradiotherapy.

\section{Circumferential resection margin}

The circumferential resection margin (CRM) is the most important surgical margin, created around the mesorectum. Nagtegaal and Quirke ${ }^{55}$ have shown that locoregional recurrence is greatly increased and overall survival halved when a tumour can be seen at or within $1 \mathrm{~mm}$ from the radial surgical plane of resection. Involved CRM (<=1 mm) was more common in patients with advanced stage, ulcerative growth pattern, poor differentiation, vascular invasion, poor TME quality, and abdominoperineal resection. The prognostic value of CRM for locoregional recurrence was even higher after neoadjuvant chemoradiotherapy or short-course radiotherapy than with no preoperative therapy. CRM is also a powerful predictor of distant metastases and overall survival. ${ }^{55}$

Despite their strong prognostic relevance, $\mathrm{R}$ status and CRM have only been used as secondary endpoints in phase 3 trials. The randomised Polish II trial ${ }^{37}$ looking at fixed T3 and T4 rectal cancer is the only exception, as the primary aim was the conversion of a primarily unresectable tumour to an R0 resectable one. The PROSPECT phase 2 and 3 randomised trial (NCT01515787) compares standard preoperative chemoradiotherapy versus preoperative chemotherapy with selective chemoradiotherapy restricted to poor responders. This trial incorporated R0 resection and time to locoregional recurrence as early stopping criteria for phase 2, and proceeded to phase 3 when stopping criteria (thresholds for both complete surgical resection and the time to local recurrence) were not met. Co-primary endpoints of phase 3 are the time to locoregional recurrence and disease-free survival. Positive resection margins have been substantially reduced $(<5-7 \%)$ with modern MRI staging, improved chemoradiotherapy, short-course radiotherapy, and surgery, and might be used as benchmark quality measure rather than an efficacy endpoint. The FOWARC phase 3 trial $^{56}$ also assessed the value of preoperative chemotherapy alone as an alternative strategy in a randomisation to either fluorouracil chemoradiotherapy followed by surgery and adjuvant fluorouracil, or the same treatment plus oxaliplatin on day one of each cycle, or four to six cycles of mFOLFOX6 followed by surgery and adjuvant mFOLFOX6. ${ }^{56}$ Despite the significantly higher rates of pathological complete response and tumour downstaging in the chemoradiotherapy groups, the primary endpoint, 3-year disease-free survival, was similar between the groups..$^{36,56}$ This study had important limitations such as complete absence of data on the use of 


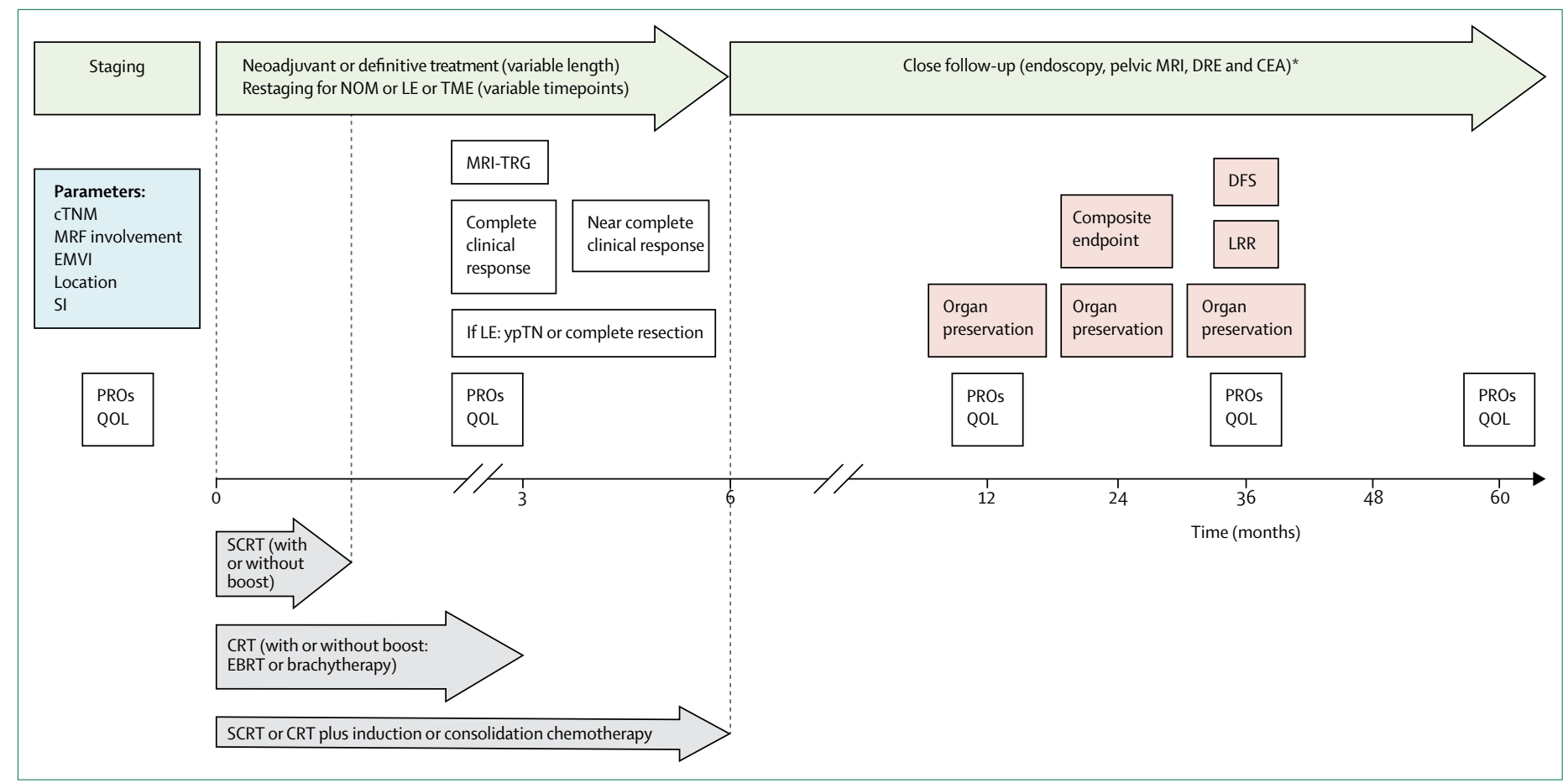

Figure 2: Clinical outcome measures for rectal cancer after neoadjuvant or definitive treatment and NOM or LE

Different preoperative or definitive treatment options are characterised by variable length and time to restaging (grey). Only endpoints used in randomised phase 2 and 3 trials are illustrated. Primary endpoints shown in red. The composite endpoint refers to novel primary endpoint of the GRECCAR 2 trial. ${ }^{8}{ }^{8}$ Timepoints of patient reported outcomes and quality of life assessment, as suggested in newer trials, are shown here. $\mathrm{NOM}=$ non-operative management. $\mathrm{LE}=$ local excision. $\mathrm{TME}=$ total mesorectal excision. $\mathrm{DRE}=$ digital rectal examination. $\mathrm{CEA}=\mathrm{carcinoembryonic}$ antigen. cTNM=clinical tumour node metastasis. MRF=mesorectal fascia. EMVI=extramural venous invasion. SI=sphincter involvement. PROs=patient-reported outcomes. QOL=quality of life. $M R I-T R G=$ magnetic resonance imaging-tumour regression grading. DFS=disease-free survival. LRR=locoregional recurrence. $S C R T=$ short-course radiotherapy. CRT=chemoradiotherapy. EBRT=external beam radiotherapy. ${ }^{*}$ The follow-up protocol of NOM and definitions of complete clinical response and near complete clinical response, as proposed by Martens and colleagues, ${ }^{58}$ are shown in the main text and appendix pp 1-2.

radiotherapy in T4 or CRM-positive tumours, no formal non-inferiority hypothesis, high rates of protocol violation (18\%) or lost to follow-up, and a dropout rate of $13 \%$. ${ }^{36,56}$

\section{Sphincter-sparing surgery}

Sphincter-sparing surgery indirectly reflects tumour response to preoperative treatment and was used in the Polish I trial as the primary endpoint. ${ }^{57}$ Despite better response in the chemoradiotherapy arm with higher pathological complete response rates and less CRM involvement, no improvement in sphincter preservation was achieved.

\section{Early endpoints used for limited surgery or non-operative management Complete clinical response}

Complete clinical response has been introduced as a clinical endpoint after the implementation of organ preservation (figure 2). Habr-Gama and colleagues ${ }^{59}$ were the first to pioneer the selective non-operative management approach in patients with complete clinical response after conventional fluorouracil chemoradiotherapy. The International Watch and Wait database reported clinical outcomes in 880 patients with complete clinical response after neoadjuvant treatment and non-operative management in 47 institutions within 15 countries. ${ }^{60}$ After a median follow-up time of $3 \cdot 3$ years, the 2-year cumulative incidence of local regrowth was $25 \cdot 2 \%$, of which $97 \%$ of tumours occurred intraluminally. The 5-year overall survival and disease-specific survival were $85 \%$ and $94 \%$, respectively. ${ }^{60}$ Similar data were shown in the OnCoRe project, ${ }^{61}$ the study by Martens and colleagues, ${ }^{58}$ and the Memorial Sloan-Kettering Cancer Center (MSKCC) database. ${ }^{62}$ There is no consensus on the best definition of complete clinical response, which would facilitate consistency among current and future clinical trials (appendix pp 1-2). Imaging modalities, namely T2-weighted MRI, diffusion-weighted MRI, PET-CT, and endoscopic ultrasound, all have limitations in predicting the pathological complete response and identifying patients with complete clinical response.

Martens and colleagues ${ }^{58}$ previously provided a pragmatic definition of complete clinical response as follows: substantial downsizing with no residual tumour or some residual fibrosis (with low signal on diffusionweighted MRI), sometimes associated with residual wall thickening due to oedema; no suspicious lymph nodes on MRI; no residual tumour at endoscopy or a small residual erythematous ulcer or scar; negative biopsies from scar, ulcer, or previous tumour location; and initially 
palpable tumour becomes non-palpable (not mandatory). First assessment should be initiated 6-8 weeks after chemoradiotherapy and repeated every 3 months. Importantly, many tumours are unreachable during a digital rectal examination and cannot be objectively documented, opposed to endoscopic or MRI images. Endoscopy and MRI do not always complement each other, which adds complexity and makes the interpretation of response challenging in the non-operative management setting. ${ }^{58}$ Randomised trials currently testing organ preservation by non-operative management, local excision, or transanal endoscopic microsurgery, and the corresponding endpoints are shown in table 2.

\section{Intermediate and long-term endpoints after surgery or non-operative management Locoregional recurrence}

Locoregional recurrence was previously the most important indicator of unsuccessful treatment in rectal cancer. Preoperative chemoradiotherapy, short-course radiotherapy, and improved TME quality have considerably reduced locoregional recurrence. The early Swedish trial, ${ }^{21}$ conducted before the routine use of TME, had randomly assigned patients to preoperative short-course radiotherapy versus surgery alone. Locoregional recurrence decreased from $27 \%$ to $11 \%$ after addition of shortcourse radiotherapy, resulting in a significant overall survival benefit. The Dutch trial ${ }^{24}$ investigated preoperative short-course radiotherapy plus TME versus TME alone, and the MRC CR07 trial ${ }^{29}$ compared preoperative shortcourse radiotherapy with postoperative chemoradiotherapy in patients with positive CRM. Both trials used locoregional recurrence as the primary endpoint and showed a significant advantage for short-course radiotherapy. However, the numerically smaller differences in locoregional recurrence $(11 \%$ with surgery alone vs $4-5 \%$ in the preoperative short-course radiotherapy groups at 3 years) did not improve overall survival, although disease-free survival was significantly improved in the MRC CR07 trial. ${ }^{29}$ The Stockholm III trial ${ }^{15}$ showed non-inferiority of short-course radiotherapy with immediate versus delayed surgery or long-course radiotherapy, using time to locoregional recurrence as the primary endpoint.

In the past decade, locoregional recurrence has been criticised as a primary endpoint in trials because of the low incidence of events and the need for long term followup to identify late recurrences. A phase 3 trial by Allegra and colleagues $^{32}$ compared preoperative chemoradiotherapy with capecitabine versus fluorouracil, both with or without oxaliplatin. The 3-year rate of locoregional recurrence was the primary endpoint, among patients who underwent R0 resection ranging from $3 \cdot 1 \%$ to $5 \cdot 1 \%$, with no significant differences between treatment groups.

\section{Local regrowth}

Local regrowth occurs in approximately $20-30 \%$ of patients with initial complete clinical response, who are managed by nonoperative management. Unlike locoregional recurrence after radical surgery, which is typically extraluminal, difficult to salvage, and might occur beyond 5 years of follow-up, local regrowth after complete clinical response usually occurs within 2 years of follow up, is mostly intraluminal, and can be easily salvaged by curative surgery. ${ }^{60}$ Thus, randomised trials testing non-operative management, local excision, or transanal endoscopic microsurgery use 12-month, 24-month, or 3-year organ preservation rates, or diseasefree survival, as the primary endpoint (table 2, figure 2).

\section{Distant control}

Distant control has not been used as a primary endpoint in phase 3 trials. Despite improvement in locoregional recurrence after preoperative chemoradiotherapy or short-course radiotherapy, overall survival was not improved in the Dutch TME and CAO/ARO/AIO-94 trials. ${ }^{1,2}$ New chemotherapy drugs including oxaliplatin and irinotecan have been tested as part of phase 1-3 trials in preoperative chemoradiotherapy. A recent metaanalysis ${ }^{63}$ evaluated the addition of platinum derivates to fluorouracil-based neoadjuvant chemoradiotherapy used for rectal cancer. In ten randomised controlled trials with 5599 patients, addition of oxaliplatin to chemoradiotherapy led to a significantly increased pathological complete response $(\mathrm{p}=0.002)$ and reduced distant recurrence $(p=0 \cdot 004)$. However, these benefits were accompanied by higher rates of grade 3-4 toxic effects with no significant improvements in disease-free survival $(\mathrm{p}=0 \cdot 07)$ or overall survival $(\mathrm{p}=0 \cdot 23)$.

\section{Disease-free survival}

Disease-free survival in adjuvant treatment trials for colon cancer is defined as the time from randomisation to local or distant recurrence, second cancer, or death from any cause. ${ }^{64}$ In a meta-analysis, ${ }^{65}$ the benefit of adjuvant treatments on 3-year disease-free survival was significantly associated with improved 5-year overall survival. Thus, 3-year disease-free survival has been accepted as a surrogate for overall survival in resectable colon cancer. Although 2-year disease-free survival was a stronger predictor for overall survival than pathological complete response after preoperative treatment in 2795 patients with rectal cancer across five phase 3 studies, ${ }^{66}$ it has not been adopted as an endpoint. The definition of disease-free survival varies between multimodal rectal cancer trials, especially regarding surgery. Some trials included patients receiving only radical surgery, whereas others included patients with progressive disease before surgery, incomplete resection, or no surgery in the definition. Adjuvant chemotherapy following standard neoadjuvant chemoradiotherapy or short-course radiotherapy, was assessed in five randomised trials (appendix p 3), but its role remains unclear because these studies (except the small ADORE trial [appendix p 3]) had low accrual, poor treatment 
compliance, suboptimal regimens, and did not show a clinical benefit for the primary endpoints, disease-free survival, or overall survival. ${ }^{67}$

\section{Composite endpoints}

Composite endpoints reduce the required sample size and cost of a trial by increasing event rates. Composite endpoints should ideally incorporate components that occur with similar frequency, are of comparable importance to patients, and are affected to a similar degree by the intervention. Criticism has been raised that these conditions are unlikely to be met in practice..$^{68,69}$ The GRECCAR 2 phase 3 trial $^{38}$ randomly assigned 148 patients with T2 or T3 lower rectal tumours, and residual tumours of $2 \mathrm{~cm}$ or less after chemoradiotherapy, to receive either local excision or total mesorectal excision. The primary endpoint was the occurrence of death, local or distant recurrence, severe surgical complications, or major morbidity 2 years after surgery. Patients with ypT0-1 in the local excision group were followed up and a completion total mesorectal excision was required for patients with ypT2-3 tumours. In the local excision group, $35 \%$ of patients needed a completion total mesorectal excision which significantly increased morbidity and side-effects. After 2 years, one or more events occurred in $56 \%$ patients in the local excision group and $48 \%$ in the total mesorectal excision group $(\mathrm{p}=0 \cdot 43)$. A similar 3-year locoregional recurrence rate was observed between the two groups $(5 \%$ vs $6 \%, \mathrm{p}=0 \cdot 68) .{ }^{38}$ The endpoint of this trial was novel, but its interpretation remains challenging because of competing risks between different individual endpoint components. ${ }^{68,69}$

\section{Patient-reported outcomes}

Patient-reported outcomes were implemented to study the effect of disease and treatment on QOL. Few phase 3 trials have reported QOL in rectal cancer. Marijnen and colleagues $^{70}$ found few differences in QOL of patients treated using total mesorectal excision with or without short-course radiotherapy, as part of the Dutch trial in 990 disease-free patients up to 2 years after randomisation. In a follow-up study, Peeters and colleagues ${ }^{71}$ examined $^{-}$ toxic effects in 597 patients using an in-house questionnaire. After a median follow up of $5 \cdot 1$ years, patients after short-course radiotherapy had significantly higher proportions of faecal incontinence with pad wearing and bowel dysfunction, and worse sexual functioning. ${ }^{70,71}$ The Nordic trial ${ }^{72}$ that compared QOL using the EORTC QLQ-C30 questionnaire after chemoradiotherapy versus radiotherapy, reported higher incidence of social dysfunction, dyspnoea, and diarrhoea in the chemoradiotherapy group, but similar overall QOL in both groups. In the Polish I trial ${ }^{73}$ that tested short-course radiotherapy versus chemoradiotherapy, no significant differences in anorectal and sexual functions, or QOL were observed between the two groups based on the QLQ-C30 questionnaire. The PRODIGE 2, phase 3 trial $^{74}$ randomly assigned patients to capecitabine chemoradiotherapy either with or without oxaliplatin and showed similar QOL in both groups using the QLQ-C30 and CR38 questionnaires.

\section{Discussion}

The Definition for the Assessment of Time-to-event Endpoints in CANcer trials project ${ }^{75}$ has been developed to provide consensus-based recommendations for clinical endpoints and facilitate consistency in reporting clinical data, but no consensus regarding the choice of endpoint in different phase trials exists to date for rectal cancer. There has been a large variability regarding primary endpoints in phase 2 and phase 3 trials, leading to intertrial inconsistency and difficulty in data interpretation.

Undoubtedly, the perfect clinical endpoint is unlikely to be established, as all endpoints have advantages and disadvantages (appendix pp 3-4). Despite these limitations, defining the most appropriate endpoints for each trial phase is important to advance progress. For rectal cancer, we propose a pragmatic approach to adjust measurement of efficacy to the specific clinical question.

For phase 1 trials, an assessment of dose-limiting toxic effects and definition of recommended dose level for phase 2 testing remain standard primary endpoints. Unlike phase 1 trials in patients with metastatic disease refractory to previous lines of treatment, phase 1 trials in rectal cancer are commonly done in treatment-naive patients treated with curative intent. Thus, when testing the toxicity and feasibility of new chemotherapy, targeted, or immunotherapy drugs added to standard chemoradiotherapy or short-course radiotherapy, or radiotherapy dose escalation, more complex phase 1 designs such as the time-to-event continual reassessment method $^{76}$ might be indicated.

In phase 2 trials where preoperative chemoradiotherapy or short-course radiotherapy are used followed by radical surgery, NAR and TRG might be more appropriate than pathological complete response for three reasons: pathological complete response did not correlate with improved overall survival in surrogate analyses and was inferior to other endpoints such as 2-year disease-free survival; ${ }^{40,41,66}$ pathological complete response represents a binary histological variable, whereas NAR and TRG might reflect treatment response and cancer biology better as they indicate a continuum of tumour regression; NAR and TRG have been validated as individuallevel surrogate markers for disease-free survival..$^{44,47}$ The NAR score takes pre-treatment cT category into account, incorporates prognostically most relevant ypN-category, and has a slightly better prognostic value for overall survival compared with pathological complete response in rectal cancer trials. ${ }^{45,48}$ NAR is also not characterised by the inherent limitations of TRG assessment, including lack of a universally approved classification system. 


\begin{tabular}{|c|c|c|}
\hline & $\begin{array}{l}\text { Disease-free } \\
\text { survival }\end{array}$ & Time from randomisation until ${ }^{*}$ \\
\hline $\begin{array}{l}\text { No resection of primary tumour because of local } \\
\text { progression or the patient being unfit for surgery }\end{array}$ & $E$ & $\begin{array}{l}\text { Date of exploratory surgery or } \\
\text { scheduled, but not done surgery }\end{array}$ \\
\hline $\begin{array}{l}\text { No resection of primary tumour because of a clinical } \\
\text { complete response and patient opts for NOM }\end{array}$ & 1 & .. \\
\hline $\begin{array}{l}\text { Limited surgery (LE or TEM) of primary tumour because } \\
\text { of near clinical complete response including curative } \\
\text { completion TME after LE or TEM }\end{array}$ & 1 & .. \\
\hline Non-radical resection of primary tumour (R2-resection) & $\mathrm{E}$ & Date of surgery \\
\hline $\begin{array}{l}\text { Locoregional recurrence after } \mathrm{R} 0 \text { or } \mathrm{R} 1 \text { resection of the } \\
\text { primary tumour }\end{array}$ & $\mathrm{E}$ & Date of locoregional recurrence \\
\hline $\begin{array}{l}\text { Local re-growth after initial clinical complete response } \\
\text { followed by curative salvage operation (R0 or R1) } \dagger\end{array}$ & I & .. \\
\hline $\begin{array}{l}\text { Non-salvageable local regrowth in case of NOM } \\
\text { management (no operation or R2 salvage resection) }\end{array}$ & $\mathrm{E}$ & $\begin{array}{l}\text { Date of diagnosis of } \\
\text { non-salvageable regrowth or date } \\
\text { of R2 salvage surgery }\end{array}$ \\
\hline $\begin{array}{l}\text { Any distant metastatic disease before, at, or after } \\
\text { surgery, or NOM management }\end{array}$ & $\mathrm{E}$ & Date of distant metastases \\
\hline Second primary colorectal cancer & $\mathrm{E}$ & Date of second colorectal primary \\
\hline Second primary other cancer & $\mathrm{E}$ & $\begin{array}{l}\text { Date of second primary, } \\
\text { other cancer }\end{array}$ \\
\hline Treatment-related death & $\mathrm{E}$ & Date of death \\
\hline Death from same cancer & $\mathrm{E}$ & Date of death \\
\hline Death from other cancer & E & Date of death \\
\hline Non-cancer-related death & $\mathrm{E}$ & Date of death \\
\hline Lost to follow up & Censor & Date of last follow up \\
\hline \multicolumn{3}{|c|}{$\begin{array}{l}\text { E=event. I=ignore. NOM=non-operative management. LE=local excision. TEM=transanal endoscopic microsurgery. } \\
\text { TME=total mesorectal excision. *Time from randomisation until, whichever event occurs first. †If local excision is } \\
\text { performed for local regrowth after initial clinical complete response, and a local recurrence occurs, then a salvage } \\
\text { operation should be done; if the salvage operation for local recurrence is performed in curative intent (R0 or R1), it should } \\
\text { not count as an event (ignore); if, however, no operation, or only an R2 resection is possible, or there is a recurrence after } \\
\text { salvage surgery, this should count as an event. }\end{array}$} \\
\hline
\end{tabular}

Table 4: Proposal for definition of disease-free survival for randomised neoadjuvant treatment trials incorporating the option of NOM

\section{Search strategy and selection criteria}

We did a literature search using PubMed, MEDLINE, Web of Science, and the Cochrane Library for fully published articles and abstracts from international meetings from Jan 1,1993 , to Sept 1, 2019, supplemented by hand searching of abstracts from international meetings between Jan 1, 2010 and Sept 1, 2019. MeSH terms or combined free terms included "rectal cancer", "clinical endpoint", "surrogate", "surrogate endpoint", "composite endpoint", "randomised trials", "phase 2/3" (or phase II/III)", "survival", "radiotherapy", "short-course radiotherapy", "chemoradiation", "preoperative", "neoadjuvant", "organ preservation", "non-operative management", "quality of life (QOL)", and "PROMs". Only papers published in English were reviewed. Only randomised phase 2 and phase 3 clinical trials with clearly defined clinical endpoints were selected, whereas single arm, prospective non-randomised trials, and studies that did not have a clear clinical endpoint definition were excluded. Unpublished ongoing randomised phase 2 and phase 3 studies were cited using either the NCT trial number, the ISRCTN registry, or the EudraCT number. Of the 625 full-text articles or abstracts assessed for eligibility, 71 publications were relevant. The final reference list was generated on the basis of relevance to the broad scope of the present review.

(NCT02008656) for total neoadjuvant treatment, the GEMCAD $1402^{18}$ trial for inclusion of aflibercept, and the NRG GI002 trial (NCT02921256) for testing new radiosensitisers.

For phase 3 trials, disease-free survival constitutes the most suitable primary clinical endpoint, despite the lack of validation as a surrogate for overall survival in rectal cancer. In the era of organ preservation, incorporating the non-operative management into disease-free survival for patients with complete clinical response is essential. Our proposal (table 4) is based on the consensus agreement for disease-free survival in the adjuvant setting for colon cancer, ${ }^{64}$ but additionally includes events occurring during neoadjuvant treatment and at surgery, also incorporating the non-operative management and local excision, or transanal endoscopic microsurgery. ${ }^{64}$

\section{Future perspectives}

The choice of primary endpoint in clinical trials remains challenging. Relying on surrogates and intermediate endpoints carries the risk of trials that might not improve long-term clinical outcome. The potential biological mechanisms that could underline poor correlation of surrogate endpoints with survival in some studies remain unclear. In the context of tumour heterogeneity, the local treatment effect on the primary tumour, as reflected by pathological complete response, might not fully encapsulate the tumour cell propensity for micrometastatic seeding."

In the era of personalised medicine, the opinion of patients' needs to be considered and they should be 
increasingly engaged in decision making. Future trials should aim to use endpoints, agreed between patients, clinicians, and regulatory authorities, as exemplified by the core outcome measures in effectiveness trials ${ }^{78}$ and the core outcome set for clinical trials of chemoradiotherapy interventions, ${ }^{79}$ initiatives in anal cancer. More data on PROs are needed, especially in the increasingly adopted setting of non-operative management.

Altogether, efforts should be made to continue evaluating surrogate and clinical endpoints using robust statistical methods. We recommend that data from large, randomised clinical trials in rectal cancer become available to establish an international database, as suggested for other clinical setting ${ }^{80}$ to allow access to all interested parties and stakeholders.

\section{Contributors}

All authors contributed to the literature search, writing or review of the manuscript, and approved the final manuscript.

\section{Declaration of interests}

We declare no competing interests. BDM has obtained funding from the National Institutes of Health (NIH), USA for research purposes that are not related to the present manuscript (2U19CA021239-35 National Cancer Institute, NIH; 1 U10 CA180858-01, National Cancer Institute, NIH).

\section{References}

1 van Gijn W, Marijnen CA, Nagtegaal ID, et al. Preoperative radiotherapy combined with total mesorectal excision for resectable rectal cancer: 12-year follow-up of the multicentre, randomised controlled TME trial. Lancet Oncol 2011; 12: 575-82.

2 Sauer R, Liersch T, Merkel S, et al. Preoperative versus postoperative chemoradiotherapy for locally advanced rectal cancer: results of the German CAO/ARO/AIO-94 randomized phase III trial after a median follow-up of 11 years. J Clin Oncol 2012; 30: 1926-33.

3 Wilson MK, Collyar D, Chingos DT, et al. Outcomes and endpoints in cancer trials: bridging the divide. Lancet Oncol 2015; 16: e43-52.

4 Buyse M, Sargent DJ, Grothey A, Matheson A, de Gramont A. Biomarkers and surrogate end points--the challenge of statistical validation. Nat Rev Clin Oncol 2010; 7: 309-17.

5 Bujko K, Nowacki MP, Nasierowska-Guttmejer A, Michalski W, Bebenek M, Kryj M. Long-term results of a randomized trial comparing preoperative short-course radiotherapy with preoperative conventionally fractionated chemoradiation for rectal cancer. Br J Surg 2006; 93: 1215-23.

6 Ngan SY, Burmeister B, Fisher RJ, et al. Randomized trial of short-course radiotherapy versus long-course chemoradiation comparing rates of local recurrence in patients with $\mathrm{t} 3$ rectal cancer: Trans-Tasman radiation oncology group trial 01.04. J Clin Oncol 2012; 30: 3827-33.

7 Prentice RL. Surrogate endpoints in clinical trials: definition and operational criteria. Stat Med 1989; 8: 431-40.

8 Buyse M, Molenberghs G, Paoletti X, et al. Statistical evaluation of surrogate endpoints with examples from cancer clinical trials. Biom J 2016; 58: 104-32.

9 Fokas E, Liersch T, Fietkau R, et al. Downstage migration after neoadjuvant chemoradiotherapy for rectal cancer: the reverse of the Will Rogers phenomenon? Cancer 2015; 121: 1724-27.

10 Francois Y, Nemoz CJ, Baulieux J, et al. Influence of the interval between preoperative radiation therapy and surgery on downstaging and on the rate of sphincter-sparing surgery for rectal cancer: the Lyon R90-01 randomized trial. J Clin Oncol 1999; 17: 2396.

11 Cotte E, Passot G, Decullier E, et al. Pathologic response, when increased by longer interval, is a marker but not the cause of good prognosis in rectal cancer: 17-year follow-up of the Lyon R90-01 randomized trial. Int J Radiat Oncol Biol Phys 2016; 94: 544-53.
12 Lefevre JH, Mineur L, Kotti S, et al. Effect of interval (7 or 11 weeks) between neoadjuvant radiochemotherapy and surgery on complete pathologic response in rectal cancer: a multicenter, randomized, controlled trial (GRECCAR-6). J Clin Oncol 2016; 34: 3773-80.

13 Evans J, Bhoday B, Sizer B, et al. Results of a prospective randomised control 6 vs 12 trial: is greater tumour downstaging observed on post treatment MRI if surgery is delayed to 12 -weeks versus 6-weeks after completion of neoadjuvant chemoradiotherapy? Ann Oncol 2016, 27: 4520.

14 Akgun E, Caliskan C, Bozbiyik O, et al. Randomized clinical trial of short or long interval between neoadjuvant chemoradiotherapy and surgery for rectal cancer. Br J Surg 2018; 105: 1417-25.

15 Erlandsson J, Holm T, Pettersson D, et al. Optimal fractionation of preoperative radiotherapy and timing to surgery for rectal cancer (Stockholm III): a multicentre, randomised, non-blinded, phase 3, non-inferiority trial. Lancet Oncol 2017; 18: 336-46.

16 Fernández-Martos C, Pericay C, Aparicio J, et al. Phase II, randomized study of concomitant chemoradiotherapy followed by surgery and adjuvant capecitabine plus oxaliplatin (CAPOX) compared with induction CAPOX followed by concomitant chemoradiotherapy and surgery in magnetic resonance imagingdefined, locally advanced rectal cancer: grupo cancer de recto 3 study. J Clin Oncol 2010; 28: 859-65.

17 Dewdney A, Cunningham D, Tabernero J, et al. Multicenter randomized phase II clinical trial comparing neoadjuvant oxaliplatin, capecitabine, and preoperative radiotherapy with or without cetuximab followed by total mesorectal excision in patients with high-risk rectal cancer (EXPERT-C). J Clin Oncol 2012; 30: $1620-27$

18 Fernández-Martos C, Pericay C, Losa F, et al. Effect of aflibercept plus modified FOLFOX6 induction chemotherapy before standard chemoradiotherapy and surgery in patients with high-risk recta adenocarcinoma: the GEMCAD 1402 randomized clinical trial. JAMA Oncol 2019; 5: 1566.

19 Rouanet P, Rullier E, Lelong B, et al. Tailored treatment strategy for locally advanced rectal carcinoma based on the tumor response to induction chemotherapy: preliminary results of the French phase II multicenter GRECCAR4 trial. Dis Colon Rectum 2017; 60: 653-63.

20 Fokas E, Allgäuer M, Polat B, et al. Randomized phase II trial of chemoradiotherapy plus induction or consolidation chemotherapy as total neoadjuvant therapy for locally advanced rectal cancer: CAO/ARO/AIO-12. J Clin Oncol 2019; 37: 3212-22.

21 Cedermark B, Dahlberg M, Glimelius B, Påhlman L, Rutqvist LE, Wilking N. Improved survival with preoperative radiotherapy in resectable rectal cancer. $N$ Engl J Med 1997; 336: 980-87.

22 Roh MS, Colangelo LH, O'Connell MJ, et al. Preoperative multimodality therapy improves disease-free survival in patient with carcinoma of the rectum: NSABP R-03. J Clin Oncol 2009; 27: $5124-30$

23 Frykholm GJ, Påhlman L, Glimelius B. Combined chemo- and radiotherapy vs. radiotherapy alone in the treatment of primary, nonresectable adenocarcinoma of the rectum. Int J Radiat Oncol Biol Phys 2001; 50: 427-34.

24 Kapiteijn E, Marijnen CA, Nagtegaal ID, et al. Preoperative radiotherapy combined with total mesorectal excision for resectable rectal cancer. N Engl J Med 2001; 345: 638-46.

25 Sauer R, Becker H, Hohenberger W, et al. Preoperative versus postoperative chemoradiotherapy for rectal cancer. $N$ Engl J Med 2004; 351: 1731-40.

26 Braendengen M, Tveit KM, Berglund A, et al. Randomized phase III study comparing preoperative radiotherapy with chemoradiotherapy in nonresectable rectal cancer. J Clin Oncol 2008; 26: 3687-94.

27 Bosset JF, Calais G, Mineur L, et al. Fluorouracil-based adjuvan chemotherapy after preoperative chemoradiotherapy in rectal cancer: long-term results of the EORTC 22921 randomised study. Lancet Oncol 2014; 15: 184-90.

28 Gérard JP, Conroy T, Bonnetain F, et al. Preoperative radiotherapy with or without concurrent fluorouracil and leucovorin in T3-4 rectal cancers: results of FFCD 9203. J Clin Oncol 2006; 24: 4620-25. 
29 Sebag-Montefiore D, Stephens RJ, Steele R, et al. Preoperative radiotherapy versus selective postoperative chemoradiotherapy in patients with rectal cancer (MRC CR07 and NCIC-CTG C016): a multicentre, randomised trial. Lancet 2009; 373: 811-20.

30 Aschele C, Cionini L, Lonardi S, et al. Primary tumor response to preoperative chemoradiation with or without oxaliplatin in locally advanced rectal cancer: pathologic results of the STAR-01 randomized phase III trial. J Clin Oncol 2011; 29: 2773-80.

31 Gérard JP, Azria D, Gourgou-Bourgade S, et al. Clinical outcome of the ACCORD 12/0405 PRODIGE 2 randomized trial in rectal cancer. J Clin Oncol 2012; 30: 4558-65.

32 Allegra CJ, Yothers G, O'Connell MJ, et al. Neoadjuvant 5-FU or capecitabine plus radiation with or without oxaliplatin in rectal cancer patients: a phase III randomized clinical trial. J Natl Cancer Inst 2015; 107: djv248.

33 Schmoll HJ, Haustermans K, Rice TJ, et al. Preoperative chemoradiotherapy and postoperative chemotherapy with capecitabine and oxaliplatin versus capecitabine alone in locally advanced rectal cancer: disease-free survival at interim analysis. Proc Am Soc Clin Oncol 2014; 32 (suppl 15): 32.

34 Hofheinz RD, Wenz F, Post S, et al. Chemoradiotherapy with capecitabine versus fluorouracil for locally advanced rectal cancer: a randomised, multicentre, non-inferiority, phase 3 trial. Lancet Oncol 2012; 13: 579-88.

35 Rödel C, Graeven U, Fietkau R, et al. Oxaliplatin added to fluorouracil-based preoperative chemoradiotherapy and postoperative chemotherapy of locally advanced rectal cancer (the German CAO/ARO/AIO-04 study): final results of the multicentre, open-label, randomised, phase 3 trial. Lancet Oncol 2015; 16: 979-89.

36 Deng Y, Chi P, Lan P, et al. Neoadjuvant modified FOLFOX6 with or without radiation versus fluorouracil plus radiation for locally advanced rectal cancer: final results of the Chinese FOWARC trial. J Clin Oncol 2019; 37: 3223-33.

37 Bujko K, Wyrwicz L, Rutkowski A, et al. Long-course oxaliplatinbased preoperative chemoradiation versus $5 \times 5$ Gy and consolidation chemotherapy for cT4 or fixed cT3 rectal cancer: results of a randomized phase III study. Ann Oncol 2016; 27: 834-42.

38 Rullier E, Rouanet P, Tuech JJ, et al. Organ preservation for rectal cancer (GRECCAR 2): a prospective, randomised, open-label, multicentre, phase 3 trial. Lancet 2017; 390: 469-79.

39 Maas M, Nelemans PJ, Valentini V, et al. Long-term outcome in patients with a pathological complete response after chemoradiation for rectal cancer: a pooled analysis of individual patient data. Lancet Oncol 2010; 11: 835-44.

40 Bonnetain F, Bosset JF, Gerard JP, et al. What is the clinical benefit of preoperative chemoradiotherapy with 5FU/leucovorin for T3-4 rectal cancer in a pooled analysis of EORTC 22921 and FFCD 9203 trials: surrogacy in question? Eur J Cancer 2012; 48: 1781-90.

41 Petrelli F, Borgonovo K, Cabiddu M, Ghilardi M, Lonati V, Barni S. Pathologic complete response and disease-free survival are not surrogate endpoints for 5-year survival in rectal cancer: an analysis of 22 randomized trials. J Gastrointest Oncol 2017; 8: 39-48.

42 Garcia-Aguilar J, Chow OS, Smith DD, et al. Effect of adding mFOLFOX6 after neoadjuvant chemoradiation in locally advanced rectal cancer: a multicentre, phase 2 trial. Lancet Oncol 2015; 16: 957-66.

43 Fokas E, Liersch T, Fietkau R, et al. Tumor regression grading after preoperative chemoradiotherapy for locally advanced rectal carcinoma revisited: updated results of the CAO/ARO/AIO-94 trial. J Clin Oncol 2014; 32: 1554-62.

44 Fokas E, Ströbel P, Fietkau R, et al. Tumor regression grading after preoperative chemoradiotherapy as a prognostic factor and individual-level surrogate for disease-free survival in rectal cancer. J Natl Cancer Inst 2017; 109: djx095.

45 George TJ Jr, Allegra CJ, Yothers G. Neoadjuvant rectal (NAR) score: a new surrogate endpoint in rectal cancer clinical trials. Curr Colorectal Cancer Rep 2015; 11: 275-80.

46 Valentini V, van Stiphout RG, Lammering G, et al. Nomograms for predicting local recurrence, distant metastases, and overall survival for patients with locally advanced rectal cancer on the basis of European randomized clinical trials. J Clin Oncol 2011; 29: $3163-72$.
47 Fokas E, Fietkau R, Hartmann A, et al. Neoadjuvant rectal score as individual-level surrogate for disease-free survival in rectal cancer in the CAO/ARO/AIO-04 randomized phase III trial. Ann Oncol 2018; 29: 1521-27.

48 Yothers G, George TJ, Allegra CJ, et al. Predictive validity of neoadjuvant rectal (NAR) score and pathologic complete response (ypCR) for overall survival (OS) as surrogate endpoints in rectal cancer clinical trial. Proc Am Soc Clin Oncol 2016; 34 (suppl 15): 3533

49 Sclafani F, Kalaitzaki E, Cunningham D, Tait D, Brown G, Chau I. Neoadjuvant rectal score: run with the hare and hunt with the hounds. Ann Oncol 2018; 29: 2261-62.

50 George TJ, Yothers G, Hong TS, et al. NRG-GI002: a phase II clinical trial platform using total neoadjuvant therapy (TNT) in locally advanced rectal cancer (LARC) - first experimental arm (EA) initial results. J Clin Oncol 2019; 37: 3505.

51 van der Valk MJM, Vuijk FA, Putter H, van de Velde CJH, Beets GL, Hilling DE. Disqualification of neoadjuvant rectal score based on data of 6596 patients from the Netherlands cancer registry. Clin Colorectal Cancer 2019; 18: e231-36.

52 Trakarnsanga A, Gönen M, Shia J, et al. Comparison of tumor regression grade systems for locally advanced rectal cancer after multimodality treatment. J Natl Cancer Inst 2014; 106: dju248.

53 Taylor FG, Quirke P, Heald RJ, et al. Preoperative magnetic resonance imaging assessment of circumferential resection margin predicts disease-free survival and local recurrence: 5-year follow-up results of the MERCURY study. J Clin Oncol 2014; 32: 34-43.

54 Sclafani F, Brown G, Cunningham D, et al. Comparison between MRI and pathology in the assessment of tumour regression grade in rectal cancer. Br J Cancer 2017; 117: 1478-85.

55 Nagtegaal ID, Quirke P. What is the role for the circumferential margin in the modern treatment of rectal cancer? J Clin Oncol 2008 26: 303-12.

56 Deng Y, Chi P, Lan P, et al. Modified FOLFOX6 with or without radiation versus fluorouracil and leucovorin with radiation in neoadjuvant treatment of locally advanced rectal cancer: initial results of the Chinese FOWARC multicenter, open-label, randomized three-arm phase III trial. J Clin Oncol 2016; 34: 3300-07.

57 Bujko K, Nowacki MP, Nasierowska-Guttmejer A, et al. Sphincter preservation following preoperative radiotherapy for rectal cancer: report of a randomised trial comparing short-term radiotherapy vs. conventionally fractionated radiochemotherapy. Radiother Oncol 2004; 72: 15-24.

58 Martens MH, Maas M, Heijnen LA, et al. Long-term outcome of an organ preservation program after neoadjuvant treatment for rectal cancer. J Natl Cancer Inst 2016; 108: djw171.

59 Habr-Gama A, Perez RO, Nadalin W, et al. Operative versus nonoperative treatment for stage 0 distal rectal cancer following chemoradiation therapy: long-term results. Ann Surg 2004; 240: 711-18.

60 van der Valk MJM, Hilling DE, Bastiaannet E, et al. Long-term outcomes of clinical complete responders after neoadjuvant treatment for rectal cancer in the International Watch \& Wait Database (IWWD): an international multicentre registry study. Lancet 2018; 391: 2537-45.

61 Renehan AG, Malcomson L, Emsley R, et al. Watch-and-wait approach versus surgical resection after chemoradiotherapy for patients with rectal cancer (the OnCoRe project): a propensity-score matched cohort analysis. Lancet Oncol 2016; 17: 174-83.

62 Smith JJ, Strombom P, Chow OS, et al. Assessment of a watch-andwait strategy for rectal cancer in patients with a complete response after neoadjuvant therapy. JAMA Oncol 2019; 5: e185896.

63 Hüttner FJ, Probst P, Kalkum E, et al. Addition of platinum derivatives to fluoropyrimidine-based neoadjuvant chemoradiotherapy for stage II/III rectal cancer: systematic review and meta-analysis. J Natl Cancer Inst 2019; 111: 887-902.

64 Punt CJ, Buyse M, Köhne CH, et al. Endpoints in adjuvant treatment trials: a systematic review of the literature in colon cance and proposed definitions for future trials. J Natl Cancer Inst 2007; 99: 998-1003.

65 Sargent D, Shi Q, Yothers G, et al. Two or three year disease-free survival (DFS) as a primary end-point in stage III adjuvant colon cancer trials with fluoropyrimidines with or without oxaliplatin or irinotecan: data from 12,676 patients from MOSAIC, X-ACT, PETACC-3, C-06, C-07 and C89803. Eur J Cancer 2011; 47: 990-96. 
66 Valentini V, van Stiphout RG, Lammering G, et al. Selection of appropriate end-points (pCR vs 2yDFS) for tailoring treatments with prediction models in locally advanced rectal cancer. Radiother Oncol 2015; 114: 302-09.

67 Carvalho C, Glynne-Jones R. Challenges behind proving efficacy of adjuvant chemotherapy after preoperative chemoradiation for rectal cancer. Lancet Oncol 2017; 18: e354-63.

68 Tomlinson G, Detsky AS. Composite end points in randomized trials: there is no free lunch. JAMA 2010; 303: 267-68.

69 Buyse M. Generalized pairwise comparisons of prioritized outcomes in the two-sample problem. Stat Med 2010; 29: 3245-57.

70 Marijnen CA, van de Velde CJ, Putter $\mathrm{H}$, et al. Impact of short-term preoperative radiotherapy on health-related quality of life and sexual functioning in primary rectal cancer: report of a multicenter randomized trial. J Clin Oncol 2005; 23: 1847-58.

71 Peeters KC, van de Velde CJ, Leer JW, et al. Late side effects of short-course preoperative radiotherapy combined with total mesorectal excision for rectal cancer: increased bowel dysfunction in irradiated patients-a Dutch colorectal cancer group study. J Clin Oncol 2005; 23: 6199-206.

72 Brændengen M, Tveit KM, Hjermstad MJ, et al. Health-related quality of life (HRQoL) after multimodal treatment for primarily non-resectable rectal cancer. Long-term results from a phase III study. Eur J Cancer 2012; 48: 813-19.

73 Pietrzak L, Bujko K, Nowacki MP, et al. Quality of life, anorectal and sexual functions after preoperative radiotherapy for rectal cancer: report of a randomised trial. Radiother Oncol 2007; 84: 217-25.
74 Etienne P-L, Francois E, Gourgou S, et al. PRODIGE 2 phase III trial neoadjuvant in rectal cancer: quality of life and results at 5 years. Proc Am Soc Clin Oncol 2016; 34 (suppl 15): 3619.

75 Bellera CA, Pulido M, Gourgou S, et al. Protocol of the Definition for the Assessment of Time-to-event Endpoints in CANcer trials (DATECAN) project: formal consensus method for the development of guidelines for standardised time-to-event endpoints' definitions in cancer clinical trials. Eur J Cancer 2013; 49: 769-81.

76 de Haan R, van Werkhoven E, van den Heuvel MM, et al. Study protocols of three parallel phase 1 trials combining radical radiotherapy with the PARP inhibitor olaparib. BMC Cancer 2019; 19: 901.

77 Rose BS, Winer EP, Mamon HJ. Perils of the pathologic complete response. J Clin Oncol 2016; 34: 3959-62.

78 Glynne-Jones R, Adams R, Lopes A, Meadows H. Clinical endpoints in trials of chemoradiation for patients with anal cancer. Lancet Oncol 2017; 18: e218-27.

79 Fish R, Sanders C, Adams R, et al. A core outcome set for clinical trials of chemoradiotherapy interventions for anal cancer (CORMAC): a patient and health-care professional consensus. Lancet Gastroenterol Hepatol 2018; 3: 865-73.

80 Bertagnolli MM, Sartor O, Chabner BA, et al. Advantages of a truly open-access data-sharing model. N Engl J Med 2017; 376: 1178-81.

(C) 2020 Elsevier Ltd. All rights reserved. 